\title{
Modernização competitiva e o Complexo Industrial e Portuário do Pecém (CIPP): rearranjos nas dinâmicas territoriais e econômicas
}

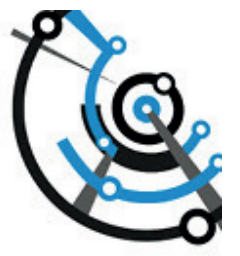

Francisco do Ó’ de Lima Júnior

Departamento de Economia; Universidade Regional do Cariri (URCA); Crato, Ceará, Brasil. ORCID: https://orcid.org/o0oo-0002-6049-3893

\section{Fernando Cezar de Macedo Mota}

Instituto de Economia da Universidade Estadual de Campinas (IE-UNICAMP); Campinas, São Paulo, Brasil.

ORCID: https://orcid.org/oooo-0002-8690-2077

\author{
Denis Fernandes Alves \\ Programa de Pós-graduação em Economia, Universidade Federal de Pernambuco (PIMES- \\ UFPE). \\ ORCID: https://orcid.org/oooo-0oo3-3322-2075
}

Recibido: 25 de abril de 2020. Aceptado: 3 de mayo de 2021.

\begin{abstract}
Resumo
No movimento de reestruturação econômica e produtiva promovendo a expansão dos fluxos internacionais impera como novo padrão de organização etapas produtivas multilocalizadas com a emergência de uma rede global de produção. Novos equipamentos de infraestrutura passam a ser concebidos promovendo arranjos de desenvolvimento regional dinâmicos. O presente trabalho objetiva analisar as conexões entre infraestrutura, economia e território no Estado do Ceará, dadas pela concepção do Complexo Industrial e Portuário do Pecém (CIPP), localizado no município de São Gonçalo do Amarante, Região Metropolitana de Fortaleza. A pesquisa é de caráter e utilizou-se dados da CEARÁPORTOS, Empresa Governamental responsável pela gestão do CIPP e outros órgãos governamentais. Observou-se que a constituição de um porto moderno, com alta capacidade, dispondo de vantagens locacionais e incentivos criados aos investimentos para comércio exterior dão importantes conexões entre infraestrutura, economia e território neste estado brasileiro, promovendo sua inserção competitiva no contexto da economia global.
\end{abstract}




\title{
Competitive modernization and the Pacém Industrial and Port Complex (CIPP): Rearrangements in territorial and economic dynamics
}

\begin{abstract}
In the movement of economic and productive restructuring promoting the expansion of international flows, multi-localized productive stages prevail as a new standard of organization with the emergence of a global production network. New infrastructure equipment starts to be designed promoting dynamic regional development arrangements. This work aims to analyze the connections between infrastructure, economy and territory in the State of Ceará, given by the conception of Pecém Industrial and Port Complex (CIPP), located in the municipality of São Gonçalo do Amarante, Metropolitan Region of Fortaleza. The research is of a character and data from CEARÁPORTOS, the Government Company responsible for the management of CIPP and other government agencies were used. It was observed that the constitution of a modern port, with high capacity, having locational advantages and incentives created for investments in foreign trade, gives important connections between infrastructure, economy and territory in this Brazilian state, promoting its competitive insertion in the context of the global economy.
\end{abstract}

Keywords: Infrastructure. Economy. Territory. Pecém Industrial and Port Complex. Palabras Clave: Infraestructura. Economía. Territorio. Complejo Industrial y Portuario de Pecém.

\section{Introdução}

As mudanças nas conformações territoriais decorrentes da reestruturação econômica e produtiva elevaram cada vez mais os fluxos de produtos ao longo do globo, a partir de uma nova lógica de divisão espacial do trabalho. Os processos econômicos passaram a articular uma imensa rede de etapas produtivas multilocalizadas, requerendo para tantas portas de entrada e saída modernas, eficientes e com grande capacidade.

As investigações acerca da promoção do desenvolvimento econômico do Estado do Ceará, como em todos os casos, se fundamentam nas necessidades de um conjunto de transformações estruturais econômicas e sociais em âmbito geral. Insere-se aí o progresso qualitativo nas melhorias das condições de vida e no avanço das relações econômicas. Um dos destaques é a dinamização produtiva e neste sentido, importante suporte é a dotação de infraestrutura.

As condições materiais que permitem a produção, a circulação e o consumo são fundamentais para o ordenamento e a produção espacial e, portanto, determinam juntamente com outras estruturas, o padrão de acumulação (Lemoso, 2009 e Macedo, 2015).

Os estudos e investigações sobre os equipamentos portuários e suas modernizações têm tido destaque no entendimento destas condições materiais, e os arranjos territoriais por elas provocados. No âmbito dos estudos sobre as infraestruturas e o desenvolvimento econômico, em nível internacional o interesse tem sido maior a partir dos anos 1990. É quando o processo de reestruturação econômica, iniciado ainda na década de 1970, dá as tessituras da hegemonia neoliberal e com ela a supremacia da era global.

Assim, dentre outros, é possível listar com uma abordagem mais geral, trabalhos como Martin e Rogers (1995) tratam da relação entre localização industrial e infraestrutura, McCann e Shefer (2004) exploram a localização, aglomeração e infraestrutura e Snieska 
e Simkunaite (2009) abordam os impactos socioeconômicos dos investimentos em infraestrutura, dentre elas a portuárias. Em estudos de caso podem ser considerados os trabalhos de D'emurge (2001) e Shia; e Guob e Sun (2017) tratando respectivamente do crescimento e infraestrutura e, sobre disparidades regionais e a dotação destas no caso da economia chinesa, Majumder (2004) com evidências no mesmo sentido para a Índia como exemplos de estudos em infraestrutura de países em desenvolvimento. Cain (1997), realiza um apanhado histórico da infraestrutura nos EUA tendo como eixo de análise sua estratégia para o desenvolvimento ao passo que as conexões entre infraestrutura e crescimento regional na União Europeia podem ser explorados no estudo de Crescenzi e Pose (2012).

Todos estes trabalhos trazem em comum as condições dadas pela infraestrutura mais geral ou específica, na dinamização econômica enquanto aspectos materiais imprescindíveis no aporte à implantação de um aparelho produtivo promotor do desenvolvimento.

Estas condições materiais são consensualmente consideradas em duas dimensões: a dimensão social e urbana de um lado e, as de caráter econômico de outro (IPEA, 2010:15). Entre as primeiras estão as que forjam o atendimento coletivo às demandas de cidadãos e de suas moradias, como habitação, saneamento, transporte urbano ao passo que as infraestruturas econômicas se referem ao suporte às atividades econômicas e produtivas em que se enquadram a disponibilidade de rodovias, ferrovias, portos, aeroportos, energia elétrica, petróleo e gás natural, biocombustíveis e telecomunicações.

O padrão de desenvolvimento decorrente da reestruturação capitalista dos dois últimos decênios do século XX e que avançou dos anos 2000 em diante, colocaram sucessivas etapas do avanço neoliberal. O conjunto de estratégias e determinações que o compõe aponta principalmente para a desregulação dos fluxos econômicos, predomínio da financeirização, aumento dos fluxos mundiais de comércio e expansão da produtividade com redução de custos.

Este conjunto de infraestruturas tem passado por transformações, acompanhando os movimentos das mudanças econômicas mais amplas. A pauta seguida é cunhada nas estratégias de inserção competitiva global redimensionando os espaços nesta lógica, tornando-os aptos à atração de investimentos em todos os seus aspectos. Nela, os nodais de transporte principalmente marítimo reafirmam seu papel estratégico nos processos de desenvolvimento, pautando juntamente com outros atributos de competitividade a inserção de cada território.

Assim sendo, o presente trabalho objetiva analisar o processo de modernização competitiva a partir dos grandes projetos estruturais de transportes com base no caso do Complexo Industrial e Portuário do Pecém (CIPP), evidenciando os seus rearranjos nas dinâmicas territoriais e econômicas.

A indagação que problematiza o caminho de sua realização está em entender quais as principais expressões dadas pelo grande projeto de infraestrutura contido no Complexo Industrial e Portuário do Pecém. Como hipótese a esta indagação, acredita-se que o estado do Ceará vivencia avanços na oferta de infraestrutura, através da implantação de grandes projetos de efeito estruturante como o caso do CIPP, dotando o seu território de condições competitivas e eficiência econômica, tornando-o plataforma de atuação dos grandes investimentos globais.

Como percurso metodológico utilizou-se inicialmente pesquisa bibliográfica e documental, pautada no recurso a trabalhos e artigos em infraestrutura portuária no Brasil e no Ceará e suas inserções globais, bem como documentos disponibilizados em sítios 
do Governo do Estado do Ceará e da CEARÁPORTOS, normatizando acerca do CIPP e seus desdobramentos. A CEARÁPORTOS é uma empresa de economia mista do Governo do Estado do Ceará, criada em 22 de dezembro de 1995, e responsável pela gestão do CIPP.

Para análise da importância do Complexo na economia e seus rearranjos territoriais e na economia, recorreu-se a dados secundários oriundos também do banco de dados da CEARÁPORTOS. O trabalho é descritivo e segue matriz metodológica históricaestrutural, evidenciando o processo de formação das estruturas e categorias em estudo e sua respectiva transformação ao longo do tempo, considerando aqui os ciclos recentes das transformações no desenvolvimento capitalista.

Para tanto, o trabalho está estruturado em três seções além desta introdução. Na seção seguinte, serão ensaiadas algumas notas sobre o cenário recente de modernização econômica cearense, processo que tem início na segunda metade da década de 1980, pela emergência de uma gestão governamental alinhada aos pressupostos neoliberais de eficiência, competitividade e inserção externa. Em seguida, serão observados como as conexões dadas pelo CIPP se inserem neste cenário de modernização, enquanto projeto importante na estratégia de inserção competitiva do Ceará. Nesta seção observa-se que o CIPP traz de forma explícita nas suas decorrências a noção de ajustes espaciais promovendo rearranjos territoriais e econômicos, apresentando o estado como plataforma atrativa aos capitais transnacionais. Na sequência são apresentadas algumas notas finais acerca deste processo.

\section{Transformações econômicas, território e infraestrutura cearenses nos anos 2000}

O padrão de desenvolvimento decorrente da reestruturação capitalista dos dois últimos decênios do século XX, e que se processa dos anos 2000 em diante, transpuseram sucessivas etapas do avanço neoliberal. O conjunto de estratégias e determinações que o compõe aponta principalmente para a desregulação dos movimentos econômicos, predomínio da financeirização capitalista, aumento dos fluxos mundiais de comércio e expansão da produtividade com redução de custos.

Uma nova divisão internacional do trabalho emerge com reordenamentos territoriais complexos, imprimindo como estratégia fundamental a busca por inserção competitiva das diversas hierarquias espaciais, promovendo a atração de investimentos em todos os seus aspectos sendo as estruturas de transportes fundamentais nesta lógica (Biachi, 2015).

No conjunto de papéis reservados a cada região do Brasil são nítidos os padrões de reprodução interna da divisão do trabalho entre elas. Figura assim de um lado as áreas com estruturas produtivas mais diversificadas e com disponibilidade de serviços mais sofisticados como o caso do Centro-Sul e das principais metrópoles distribuídas pelos diversos estados ${ }^{1}$. Os seus respectivos vínculos à economia internacional são processualmente mais diretos, tendo em vista que nestes espaços estão as sedes ou filiais das grandes corporações e grupos econômicos de ação transnacional.

De outro lado, com destaque que se expande com maior força nas duas últimas décadas dado pela reconfiguração da economia mundial, emergem áreas de destaque na 
produção de bens primários de grande interesse internacional. Áreas distribuídas de acordo com a disponibilidade de recursos naturais.

Um dos mais evidentes produtos foi um processo de rearranjo territorial e tal fato é atestado no vasto conjunto de trabalhos e pesquisas que investigam as implicações da inserção brasileira à dinâmica das mudanças do sistema capitalista mundial e seus impactos espaciais.

No tocante ao contexto cearense, este processo principia com os deslocamentos associados à sequência de ações, programas e políticas que caracterizaram a entrada do estado nas rodadas recentes da acumulação capitalista, sinalizando a sua modernização econômica e produtiva, acoplada àquele conjunto de mudanças econômicas mais amplas, acima referidas. O quadro mais perceptível considera a segunda metade dos anos 1980 como diferencial na gestão pública estadual, marcada pelo alinhamento ao paradigma de regulação fundado na eficiência de gestão, modernização econômica, renovação das políticas públicas pautada em ajustes fiscais, financeiros, administrativos e infraestrutural ${ }^{2}$.

O plano das políticas de promoção do desenvolvimento e diversificação econômica, neste contexto, elegeu como suporte maior para sua condução três grandes eixos: a indústria incentivada, o turismo e a promoção da agricultura irrigada. Na razão que justificou cada um dos eixos estava em comum: i) a necessidade de reestruturação dos setores envolvidos, até então com organização tradicional; ii) o redimensionamento das políticas públicas com a adequação/criação de instâncias institucionais para tanto; iii) o aproveitamento das potencialidades eleitas em diversos diagnósticos elaborados por órgãos de planejamento estaduais e consultorias realizadas por instituições multilaterais internacionais.

A indústria incentivada, tida como capaz de absorver o contingente de mão de obra, inicialmente esteve sob a órbita de segmentos mais tradicionais da Indústria de Transformação que se modernizaram. Dentre eles os setores de calçados, têxtil, alimentos e bebidas com presença marcante na vocação estadual decorrente inclusive das estruturas produtivas montadas no seu processo de formação econômica. A diferenciação é encontrada em dois elementos. De um lado a interiorização dos ramos mais intensivos no uso do fator trabalho, mobilizados pela oferta agressiva de incentivos de diversas ordens, ampliados à medida que a realização do empreendimento se distanciava da Região Metropolitana de Fortaleza (RMF). Assim, os principais centros urbanos do interior passam a receber unidades industriais principalmente de calçados, vindos de outras regiões do Brasil.

Em outra ordem estavam as atividades caracterizadas por uma relação capital/trabalho mais elevada e, portanto, mais tecnificadas, diversificadas e modernas, que permaneciam próximas à RMF. Apesar de ser o espaço com melhor disponibilidade de infraestrutura, seria necessário maior aporte neste campo, considerando a gradativa diversificação e complexificação dos setores induzidos aqui. O destaque foi o avanço na implantação do segmento de semielaborados, com evidência para a siderurgia, inaugurando uma nova etapa da diversificação produtiva do estado.

2 A maior parte dos estudos que investigam o desenvolvimento do Estado do Ceará nas últimas décadas denomina a inflexão administrativa e econômica ocorrida nos anos 1980 e aprofundada nas três décadas seguintes de "Governos das Mudanças". Para aprofundamentos consultar Macedo, Morais e Lima Júnior (2014), Amaral Filho (2003), Bonfim (2002). A designação é dada ao ciclo de governos estaduais que se sucedem de 1987 até 2002. Entretanto, a sequência posterior tem alinhamento administrativo ao que prevaleceu até então, pela continuidade dos princípios de gestão bem como pelo aprofundamento das ações e políticas pautadas no mesmo receituário. 
No âmbito do turismo, privilegiaram-se as atratividades litorâneas. A extensa faixa costeira, a paisagem encantadora das praias caracterizada por mar aberto, a boa iluminação solar, o panorama propício aos adeptos do veraneio, direcionou ações de atratividade turística voltada principalmente ao público internacional. Em momento posterior, os circuitos alternativos dos sertões e serras, com os atributos culturais e roteiros naturais, foram incluídos com atenção secundária.

No último eixo, o reordenamento da agricultura estadual pautado na promoção da agricultura irrigada teve importantes implicações. Reproduzindo o modelo considerado exitoso de outras experiências nordestinas - como os casos de Petrolina-Juazeiro, no vale do Rio São Francisco entre Pernambuco e Bahia e Assú-Mossoró, na bacia dos rios Assú e Apodi -, foram definidas algumas culturas dentro do segmento da fruticultura, considerando a aceitabilidade no mercado internacional. Além da montagem de um aparato institucional com a criação de órgãos específicos para os programas aqui implantados, foi também posto em prática uma arrojada política de otimização e disponibilidade de recursos hídricos. Nesta ótica, produção de frutas como melão, melancia, mangas colocam o Ceará no circuito da fruticultura nacional como uma das estratégias de expansão de suas exportações.

Os três eixos acima designados concebem um padrão que, como principal imperativo, promoveu rearranjos territoriais do estado para atendimento das suas funcionalidades, enquanto projeto de desenvolvimento bem delimitado. A noção de seletividade espacial, surgimento de novas áreas dinâmicas, privilegiando determinadas regiões do Estado convergentes com os atributos postos pelos eixos privilegiados é evidente. Adicionalmente, entrou na agenda colocada pela dotação de condições propícias, a necessidade de investimentos em infraestrutura para a promoção de cada um deles, atendendo às suas especificidades tendo em vista ainda que são campos que exigem um estoque infraestrutural de grande envergadura.

O quadro apresentado reforça a visão de que novos territórios vão surgindo promovendo a especialização cada vez maior dos lugares, forjando sua inserção mais ampla com base nestas especializa0ções e promovendo a seletividade de em diversas escalas, sentidos, fatores e valores (Silveira, 2009).

\section{As conexões dadas pelo Complexo Industrial e Portuário do Pecém}

No conjunto de transformações vivenciado pela economia cearense e acima apresentado em linhas mais amplas, o veio condutor foi direcionado para o acompanhamento do movimento mundial de flexibilização e de reestruturação econômica. A disponibilidade de bases permitindo a inserção nos fluxos caracterizados por uma divisão internacional do trabalho se tornou imperativo condicionante. Dentre elas, a base para movimentos de transportes eficientes e modernos, caracterizadas como grandes pontos de intercâmbio permitindo rapidez na emissão/recepção de mercadorias, conforme apontam Lima e Batista (2005). A implantação de um porto moderno atendendo a tais critérios passa a fazer parte das plataformas de políticas públicas do estado do Ceará.

A história portuária cearense está bem articulada à formação econômica deste estado, com destaque à reorientação econômica e territorial dada pela sua inserção no plano da economia internacional da Primeira Revolução Industrial. Já a partir de fins do século XVIII, o fornecimento do algodão como matéria-prima fundamental coloca a necessidade de um porto no meio da costa cearense, na capital Fortaleza, que até então não assumiu papel relevante no panorama das aglomerações urbanas polarizadoras da província (Lima Júnior, 2014). 
Inicialmente o embarcadouro com estrutura deficiente localizado próximo aos galpões de armazenamento de algodão serviu de porto durante muito tempo, derivando da sua localização um conjunto de estruturas urbanas como a alfândega, as casas comerciais, dentre outros, nas proximidades da parte central da cidade. Somente nos anos 1950, na extensão das preocupações com o planejamento voltado para a promoção econômica, tem-se as melhorias do Porto do Mucuripe, situado na parte leste de Fortaleza. Esta estrutura havia sido implantada como requerimento da ampliação das exportações agrícolas na década de 1940:

O porto do Mucuripe, criado em 1938 e iniciado seu funcionamento em 1941, ao se inserir na cidade de Fortaleza, passou a ser o principal ponto de escoamento da produção agrícola do Ceará e, até a operação do porto do Pecém, foi o principal porto do Estado. Nos anos 1950 a 1970 atende, essencialmente, ao comércio atacadista e as atividades de exportação estaduais, destacando-se, nesse momento, o algodão em pluma, a cera de carnaúba e o óleo de oiticica, sendo os seus principais produtos da economia cearense, até então. Junto a esses se destacam ainda óleos vegetais, couros, peles e lagostas (Teles, 2015:150).

Ao longo dos anos 1960 a 1980, o Mucuripe passa a receber e consolidar um amplo conjunto de infraestruturas como ramal da ferrovia, pavimentação de ligação às principais rodovias, grandes armazéns, além da implantação de um conjunto de fábricas com destaque para moinhos de trigo para a indústria de alimentos. Entretanto, algumas restrições se acumularam, delineando estrangulamentos para as demandas de modernização.

Dentre elas destacam-se a pouca disponibilidade de retroárea para expansão tendo em vista o crescimento da área urbana de Fortaleza em direção à parte litorânea leste da cidade, o restrito espaço para a implantação de berços de atracação e, principalmente, um canal de profundidade de dez metros, o que é considerado baixo calado de atracação. As condições naturais do porto não permitiram o avanço de melhorias considerando que sua localização, numa área suscetível ao grande movimento das águas marítimas, torna ineficiente as grandes obras de dragagem, realizadas ao longo destes anos.

Estas restrições, adicionadas às possibilidades de um complexo produtivo mais avançado junto ao porto foram decisivas. Dentre estas possibilidades estavam: implantação de indústria de grande porte e de setores diversificados; condições de expansão como é comum ao tipo de transporte marítimo; disponibilidade de grandes armazéns para atracagem de navios de calado elevado. Estudos preliminares foram realizados em toda a costa cearense na busca da área mais adequada, sendo feito levantamentos em Camocim, Paracuru, Fortim e Pecém; sendo este último o lugar definido para tanto.

Os estudos para implantação da nova estrutura portuária na área metropolitana de Fortaleza tiveram início em 1995, culminado com a implantação do novo porto, denominado de Complexo Industrial e Portuário do Pecém (CIPP). O Quadro 1 apresenta sua cronologia.

Quadro 1. Cronologia de implantação e funcionamento do CIPP (1995-2002). Fonte: CEARÁPORTOS (2018).

1995 (março)

1995 (julho/dezembro)
Navios da Marinha do Brasil iniciam levantamentos ecobatimétricos na costa do Ceará

Concepção do Complexo Industrial e Portuário do Pecém e contratação de projetos básicos de engenharia 


\begin{tabular}{ll}
\hline 1996 (maio) & $\begin{array}{l}\text { Início das obras do Terminal Portuário do Pecém e obras de } \\
\text { infraestrutura }\end{array}$ \\
\hline 1998 (abril) & Conclusão das obras da Rodovia de Acesso \\
\hline 1999 & $\begin{array}{l}\text { Conclusão das obras da Ponte de Acesso e do Píer 1 do Terminal e do } \\
\text { Sistema Elétrico do CIPP }\end{array}$ \\
\hline 2000 & Conclusão das obras do Píer 2 \\
\hline 2001 & Conclusão do Quebra-mar \\
\hline 2001 (junho) & $\begin{array}{l}\text { Assinatura do Contrato de Adesão no og1/2001 pelo Governo do Estado } \\
\text { do Ceará e Ministério dos Transportes }\end{array}$ \\
\hline 2001 (novembro) & Início das operações comerciais do Terminal \\
\hline 2002 (março) & Inauguração Oficial do Terminal Portuário do Pecém \\
\hline 2002 (abril) & Alfandegamento a Título permanente pela SRRF da 3a Região \\
\hline
\end{tabular}

Desta forma, para a nova etapa do modelo de desenvolvimento cearense foi instalado um equipamento infraestrutural reunindo as condições acima apontadas de dispor de uma conexão fixa de grande densidade técnica num complexo produtivo, para se constituir na base produtiva moderna de inserção global da economia e do território cearenses.

No campo normativo e de gestão, foi determinada a Empresa CEARÁPORTOS, do Governo do Estado do Ceará, como responsável pela Gestão do CIPP. Os equipamentos geridos pela CEARÁPORTOS, de acordo com a descrição da própria empresa em sua página oficial, agrupam as instalações do CIPP em quatro grandes conjuntos, de acordo com as seguintes descrições:

» Instalações Gerais e de Administração: Portaria central; Sede administrativa; Instalações para órgãos federais (Ministérios da Fazenda, Agricultura, Justiça, Meio Ambiente e da Saúde); Instalações de órgãos estaduais (Secretarias da Fazenda e da Agricultura); Instalações Administrativas da Zona de Processamento das Exportações (ZPE);

» Instalações de Acostagem: i) com píer para granéis sólidos e cargas não conteinerizadas; píer de $1.730 \mathrm{~m}$; ii) pier de granéis líquidos e gases liquefeitos de $2.143 \mathrm{~m}$ para atender produtos derivados de petróleo (gasolina, diesel, querosene de aviação, óleo combustível, G.L.P) e outros combustíveis; iii) pier de granéis sólidos, para carga geral conteinerizada e não conteinerizada de $2.502 \mathrm{~m}$ destinado ao atendimento de cargas siderúrgicas em geral, contêineres, cargas superdimensionadas, cargas não conteinerizadas e granel sólido; iv) estrutura de correias; v) todas as instalações de suporte e acesso aos píeres. Estes equipamentos têm localização off-shore;

» Instalações de Armazenagem: i) pátio não coberto de armazenagem com capacidade para quase 900 contêineres refrigerados e 16 mil TEU's $^{3}$ com ampla capacidade de armazenagem para bobinas, chapas planas, rolos de fios máquina, vergalhões; ii) dois armazéns que juntos somam área coberta de $16.250 \mathrm{~m} 2$ e uma Inspeção Aduaneira de 1,8 mil m2;

» Equipamentos Portuários: i) 05 guindastes sobre pneus com capacidade de 320 toneladas; guindastes de múltiplos uso sobre trilhos com capacidade de 45 toneladas esteira tubular transportadoras de minérios com capacidade de 2,4 toneladas por

3 Nos conceitos técnicos acerca de infraestrutura portuárias, de acordo com a Agência Nacional de Transportes Aquaviários (ANTAQ), TEU's se referem à unidade utilizada para conversão da capacidade de contêineres de diversos tamanhos ao tipo padrão ISO de 20 pés (http://antaq.gov.br/Portal/Anuarios/Portuario20og/termos.htm). 
hora; braços de carregamento; descarredor de granel com capacidade de , 125 tonelada por hora; conjunto de 02 e 04 balanças rodoviárias com capacidade respectiva de 80 e de 100 toneladas.

Para o Governo Estadual, a consolidação não só do Porto, mas de todo o CIPP se inseriu na pauta das prioridades para avançar sobre as fragilidades existentes nas portas de acesso ao comércio exterior. Como destaca Monié (2015:111), este aspecto é considerado um ponto crítico para toda a economia brasileira que compromete a sua inserção competitiva. Nas infraestruturas para acessar o CIPP por diversas vias, uma incisiva ação dos governos municipal, estadual e federal permitiu disponibilizar condições tráfego com a pavimentação de rodovias e outras estruturas

O porto do Pecém foi projetado numa área estratégica de fácil acesso com as rodovias federais e estaduais mais importantes do Estado do Ceará. Eixos principais: BR-222: Rodovia federal, principal via de acesso às instalações portuárias do Pecém. Interliga a capital, Fortaleza, à região setentrional do Estado e aos estados mais ao norte do País; BR-116: mais importante rodovia federal do estado, interligando a capital aos estados do sul do Brasil. A partir das instalações do terminal, pode-se ter acesso a essa rodovia através do anel viário que também será utilizado como via de interligação entre o Complexo Industrial Portuário do Pecém - CIPP e os Distritos Industriais de Maracanaú, Horizonte, Pacatuba e Eusébio; CE-422: Rodovia estadual, conhecida como Via Portuária, com 20,5 km de extensão e $12 \mathrm{~m}$ de largura, interliga a BR-222 às instalações portuárias. Essa via, juntamente com a BR-222, é uma das principais vias de escoamento de tráfego de veículos de carga que se destinam ou que têm origem nas instalações do terminal. (Lima e Batista, 2005:7730).

Portanto, a concepção do Complexo inseriu na economia e no território do Ceará as fronteiras mais contemporâneas da denominação de um porto moderno e competitivo: permitiu distanciamento/ampliação dos espaços retroportuários para implantação de parque industrial diversificado, uso de tecnologias para plataformas conteinerizadas, calados para embarcações de elevado porte, legislações permitindo desregulamentações, nodais complementares de integração terrestre, fixação de zona com gestão direcionada ao processamento e comercialização internacional, dentre outros.

As vantagens competitivas do Pecém passam a ser exploradas como um dos grandes atributos do portfólio do desenvolvimento do Ceará. A sua menor distância dos grandes portos europeus e americanos com uma média de 6 a 7 dias de viagem, bem como nas principais rotas de ligação com a Ásia coloca-o em situação de vantagem quando comparado com outros portos do Nordeste e do Brasil. A Figura 1 apresenta a localização do CIPP, destacando sua posição estratégica na costa da América do Sul. 

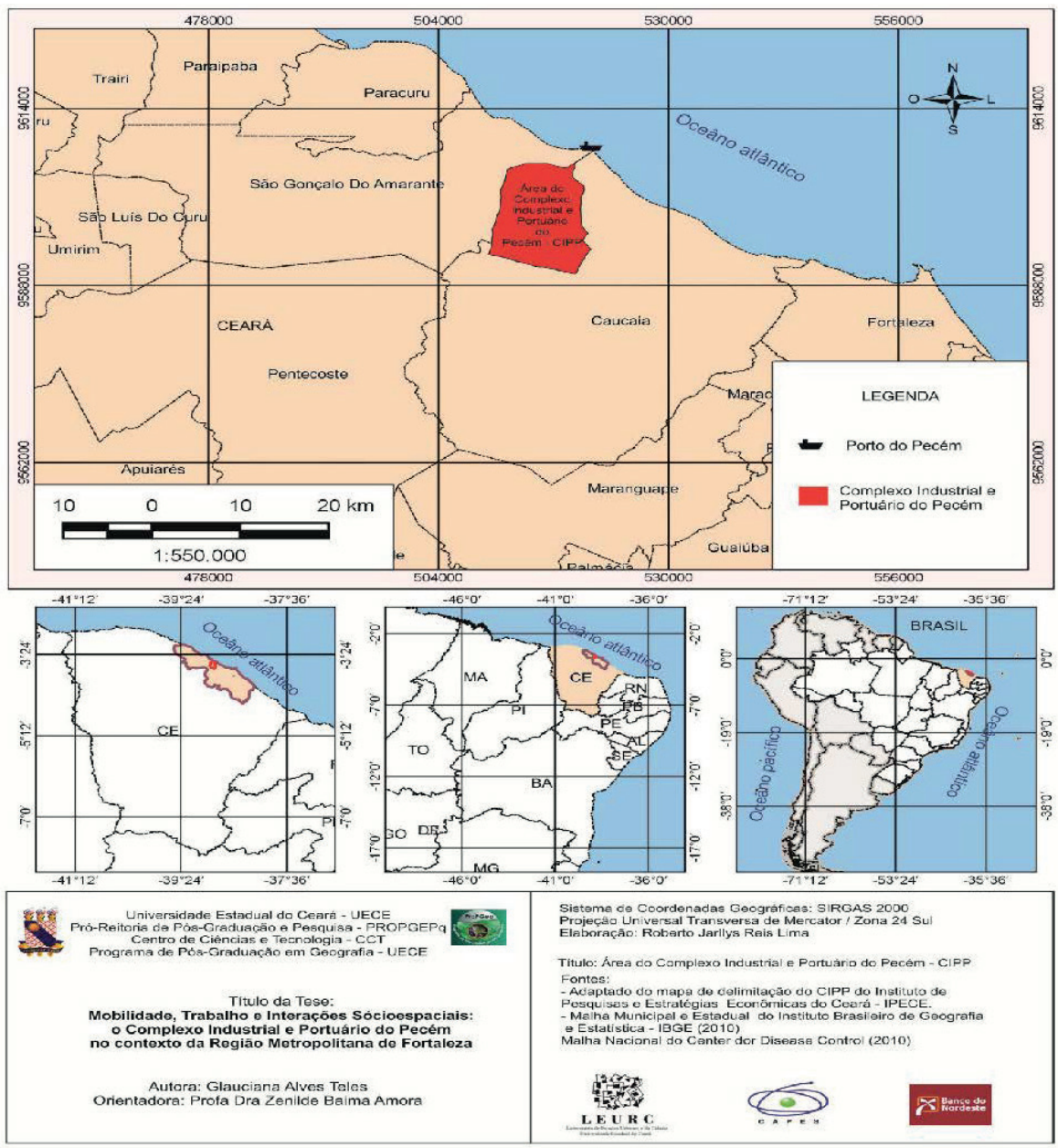

Figura 1. Complexo Industrial e Portuário do Pecém (CIPP), localização. Fonte: Teles (2015:133).

Com a disposição destas estruturas descritas, implantadas gradativamente a partir da segunda metade dos anos 1990, o Ceará passa a participar de maneira agressiva na montagem do aparato que insere seu território de forma mais nítida no ambiente de reestruturação econômica e produtiva mundial. Ao se apresentar como plataforma para abrigar/participar das etapas da multilocalização produtiva em rede global conforme apresentado por Monié (2011:299), o CIPP se coloca como porta de entrada e saída no complexo de redes de valor agregado mundial, funcionando o território cearense nesta lógica.

Aspectos de ordem física e da própria formação econômica evidenciam ainda mais a magnitude dos rearranjos provocados pela implantação do CIPP, tanto do ponto de vista dos determinantes territoriais como da diversificação econômica.

Nos determinantes territoriais, o Ceará apresenta condições físicas e naturais distintas das áreas de exportação dinamizadas com maior vigor nas duas últimas décadas, como a fronteira agrícola e/ou regiões com disponibilidade de recursos minerais. Naturalmente, estas áreas se propõem em primeiro plano às instalações infraestruturais que acompanham as tendências de suas estruturas produtivas. No caso cearense, conforme retratado na seção anterior, nos movimentos da transformação econômica pelos quais passou o estado, imperou a necessidade de ajustes espaciais de primeira ordem modernizando setores e, pari passu, dotando-o de infraestrutura. 
Ainda no Do ponto de vista dos determinantes territoriais, além de alterar a própria configuração da RMF com a incorporação do município de São Gonçalo do Amarante a esta Região Metropolitana ${ }^{4}$, as instalações do porto cumpre/cumprirá sua integração territorial no contexto mais imediato e também nacional, por intermédio de conexões emanadas de outras estruturas às demais economias regionais. Algumas de destaque são: i) a integração hídrica que permitiu o abastecimento de elevado montante de água, utilizado nas atividades termelétricas e de siderurgia, alcançadas pelo fornecimento do reservatório Castanhão, na Mesorregião Jaguaribe, juntamente com um complexo de transposição formado por adutoras e pelo Canal da Integração; na diversificação das fontes energéticas; ii) as provisões de gás natural liquefeito (GNL) para regaseificação, possibilitada pelo gasoduto Guamaré-Pecém, que interligou o CIPP à produção vinda do Rio Grande do Norte. Evidenciando que este foi o primeiro terminal de regaseificação do Brasil e que a regaseificação consiste em processos de mudanças térmicas entre águas e produtos de combustão de gás natural. (Lemos, 2010:18; Carvalho, 2008:1) e; iii) ainda em curso e sem prazos de concretização final, a ligação interportuária PecémSuape (em Recife) através da ferrovia Transnordestina, e entre estes e o complexo agrícola no sul piauiense e oeste baiano. No Ceará os trechos são Pecém/CE - Missão Velha/CE (527 km de extensão) e Missão Velha/CE - Salgueiro/PE (96 km); entre Pernambuco e Piauí (Lima Júnior, 2014:140).

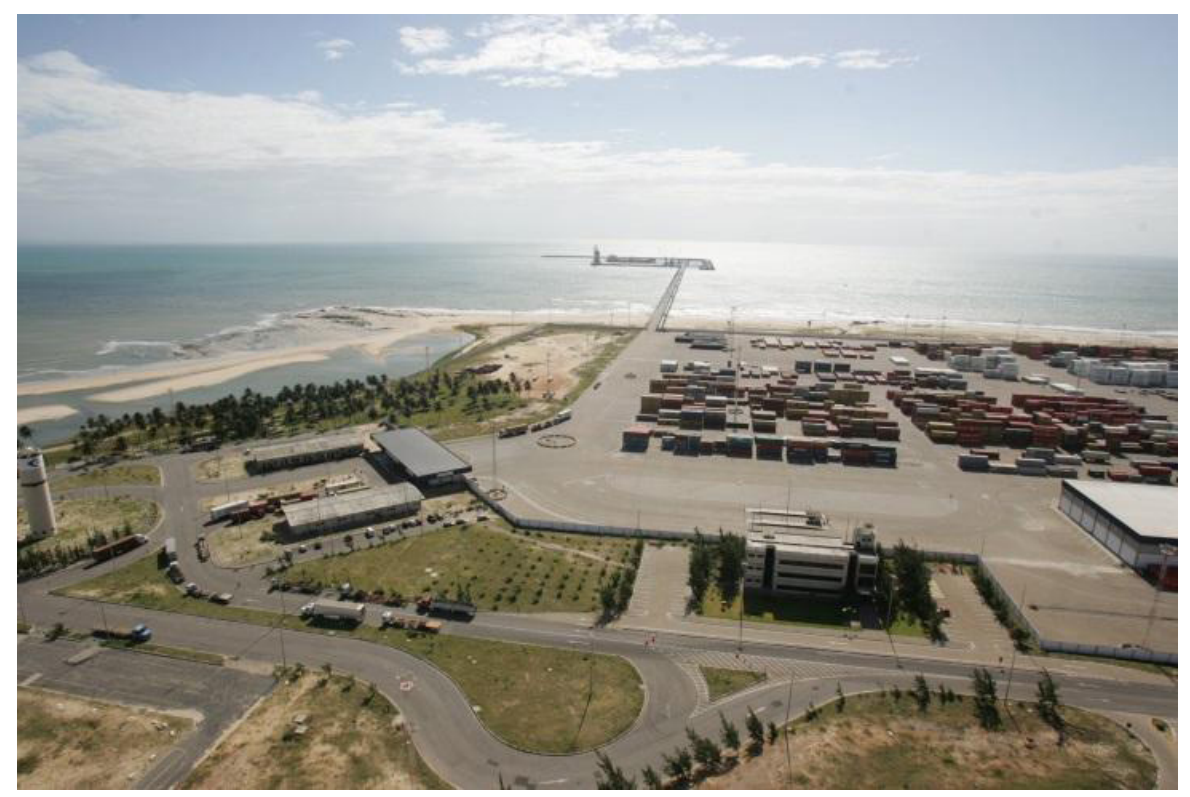

Figura 2. Complexo Industrial e Portuário do Pecém (CIPP), vista da infraestrutura de armazenagem. Fonte: ADECE (2018).

Assim sendo, a implantação do CIPP e sua consolidação se constituíram em ferramenta orgânica na concepção do plano econômico de desenvolvimento, fundado na promoção da tríade indústria incentivada, turismo e agricultura irrigada. Cada segmento destes envolve fluxos de fatores que exigem portas de entrada e saída mais eficientes, principalmente para a indústria e agricultura aqui consideradas tendo em vista seu direcionamento ao mercado externo. Ademais, estão explícitas as estratégias de expansão industrial via aprofundamento dos encadeamentos produtivos, com diversificação em ramos da siderurgia, termoelétrica e, ainda em fase de prospecção, a petroquímica. 
Já no âmbito da economia, além dos desdobramentos das transformações territoriais discorridas acima, um ativo de destacado efeito econômico vindo com o CIPP foi a reconfiguração pela implantação da Zona de Processamento de Exportações (ZPE) dentro do Complexo do Pecém. Consideradas como "áreas que funcionam como espécies de condomínios industriais, isentos de impostos, voltados essencialmente à exportação e com facilidades para importar insumos e matérias-primas" (Iaquinto, 2012:52), a ZPE trouxe possibilidades de atração de grandes conglomerados internacionais a partir do conjunto de incentivos estabelecidos.

Atualmente dentre as principais empresas que se instalaram na ZPE do CIPP estão a Companhia Siderúrgica do Pecém, a Vale Pecém, a White Martins, a Phoenix do Brasil, a Companhia Industrial de Cimento de Apodi, a Termo Ceará Ltda. (Petrobrás) (ZPE Ceará, 2018). Como se observa, estas empresas atuam nos setores pesados da indústria, siderúrgica, minério de ferro, fabricação de gases industriais, serviços siderúrgicos variados, dentre eles o manuseio de escória e a recuperação e dimensionamento de sucata de metal.

A implantação da indústria de base, representada pelo CIPP e por sua ZPE, ainda que predominantemente nas fases de processamento, inaugurou outro momento da industrialização do Ceará. Até então, a atividade industrial do estado voltava-se quase que exclusivamente para a indústria de bens de consumo não duráveis, forte tradição de sua matriz produtiva. A modernização destes setores se dera em dois momentos importantes da história da industrialização estadual sendo o primeiro na fase do desenvolvimentismo planejado por intermédio da Superintendência para o Desenvolvimento do Nordeste (SUDENE), que no Ceará é observado mais nitidamente na década de 1970, e o segundo na fase de mudanças na gestão política pela emergência dos governos de paradigma modernizante, no final dos anos $1980 \mathrm{em}$ diante.

Assim, na estratégia de internacionalização da economia cearense delineada com o objetivo de tornar o estado um ponto de intercâmbio dos fluxos globais, o Complexo foi um dos maiores investimentos ${ }^{5}$. A evolução do crescimento do movimento de cargas de 2012 em diante é apresentada no gráfico da Figura 3, pelo número de navios e pelo volume movimentado. A taxa de crescimento deste volume é de $29,2 \%$ a.a. no período de cinco anos, entretanto, o destaque maior é para a fase após 2015, quando tem início a operação da Companhia Siderúrgica do Pecém, considerada como o maior empreendimento do Complexo.

Um elemento importante é a capacidade de carga dos navios que atracam no porto demonstrando o seu elevado porte na recepção de embarcações que exigem profundidade de $15 \mathrm{~m}$. As cargas mais que triplicam ao passo que o número de navios cresce $6 \%$. 


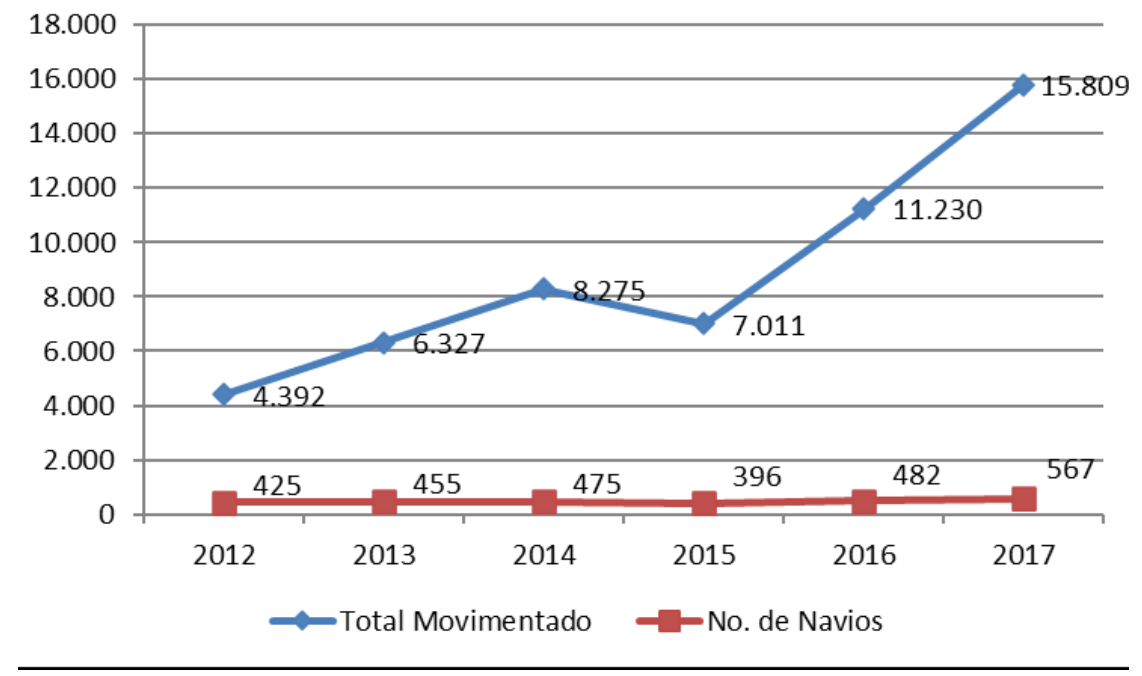

Figura 3. Movimentação no Porto do Pecém Número de Navios e Total Movimentado em mil ton. (20122017). Fonte: CEARÁPORTOS (2017).

Ainda que com a implantação da Siderúrgica a sua produção tenha elevada participação no total movimentado pelo porto de $2015 \mathrm{em}$ diante, há uma diversificação com a participação de outros produtos conforme é possível observar nos Quadros 2 e 3. Como estava planejado, o Pecém tinha como intuito ser um equipamento a serviço da integração econômica nordestina e nacional no território cearense, sendo consolidado tal aspecto quando se observa as estatísticas de sua movimentação. Segundo o Mensário Estatístico de 2017 da CEARÁPORTOS, do total das exportações de frutas feitas pelo Porto no ano de 2017, 49,8\% eram de produção potiguar, 24,2 do próprio Ceará, 13,9\% tinham origem no estado do Pernambuco, $11,4 \%$ na Bahia e $0,7 \%$ de outros estados. (CEARÁPORTOS, 2017).

A ótica expressa pela concepção e funcionamento do CIPP, vinculada à lógica da dinâmica urbano-regional na sua atual configuração de inserção competitiva, explicita o efeito do esforço exportador como estratégia fundamental conforme apontado por Macedo (2015), que coloca o território e a economia nacional a serviço dos grandes fluxos. As estruturas de transportes instaladas diretamente ou com desdobramentos do Pecém, reiteram o que mostra Silveira (2015:52), de que:

são uma base importante para as reestruturações econômicas, mormente, quando nos referimos às alocações e às realocações de atividades produtivas e de consumo no espaço, à ampliação da mobilidade geográfica do capital e ao surgimento e desaparecimento de diversos clusters econômicos; [e] podem ser utilizados como fatores de desenvolvimento a partir da ampliação da base produtiva nacional (em especial de bens de capital e construção civil pesada) e da geração de um efeito multiplicador, via parcerias público-privadas, parcerias internacionais, dentre outros.

No bojo da atração de investimentos, as economias de municípios que polarizam macrorregiões vizinhas ao porto tiveram impactos positivos, como a expansão das exportações de municípios como Itapipoca e Sobral, demonstrado por Lima Júnior (2014). Os Quadros 2 e 3 confirmam ao evidenciar o movimento das exportações e das importações realizadas pelo CIPP nos anos de 2015 a 2017. Observa-se que o maior crescimento das exportações, expresso pela movimentação de longo curso, está nos setores econômicos priorizados no conjunto de políticas direcionadas à estrutura produtiva do Ceará. Os dois ramos de maior exportação são ferro fundido, ferro e 
aço, advindos da Siderúrgica e, frutas em cascas, cítricos e melões, provenientes da modernização da agricultura via complexos irrigados de fruticultura para exportação.

No âmbito das importações, as principais movimentações são direcionadas a setores de insumos para as atividades econômicas exportadoras, dentre elas se destacam insumos para as atividades agrícolas (Adubos e Fertilizantes), Ferros Fundido e Aço Bruto para a siderurgia e, a grande participação de combustíveis. É importante observar que não obstante o crescimento das exportações, o movimento de importações ainda é maior.

Quadro 2. Movimentação de mercadoria por tipo de carga no Porto do Pecém (2017). Fonte: CEARÁPORTOS (2017).

\begin{tabular}{|c|c|c|c|}
\hline MOVIMENTAÇÃO & 2015 & 2016 & 2017 \\
\hline \multicolumn{4}{|l|}{ EXPORTAÇÕES } \\
\hline FERRO FUNDIDO, FERRO E AÇO & 21.118 & 587.556 & 2.615 .267 \\
\hline FRUTAS; CASCAS DE CÍTRICOS E DE MELÕES & 211.613 & 213.600 & 201.035 \\
\hline $\begin{array}{l}\text { COMBUSTÍVEIS MINERAIS, ÓLEOS MINERAIS E } \\
\text { PRODUTOS DE SUA DESTILAÇÃO; MATÉRIAS } \\
\text { BETUMINOSAS }\end{array}$ & & 332.550 & 121.511 \\
\hline PLÁSTICOS E SUAS OBRAS & 5.149 & 58.590 & 58.375 \\
\hline PREPARAÇÕES ALIMENTÍCIAS DIVERSAS & 40.682 & 52.547 & 50.065 \\
\hline $\begin{array}{l}\text { SAL; ENXOFRE; TERRAS E PEDRAS; GESSO, CAL } \\
\text { E CIMENTO }\end{array}$ & 29.419 & 26.058 & 29.268 \\
\hline $\begin{array}{l}\text { CALÇADOS, POLAINAS E ARTEFATOS } \\
\text { SEMELHANTES, E SUAS PARTES }\end{array}$ & 13.809 & 11.440 & 14.163 \\
\hline $\begin{array}{l}\text { OUTROS METAIS COMUNS; CERAMAIS } \\
\text { (CERMETS); OBRAS DESSAS MATÉRIAS }\end{array}$ & 7.529 & 15.559 & 13.504 \\
\hline $\begin{array}{l}\text { GORDURAS E ÓLEOS ANIMAIS OU VEGETAIS; } \\
\text { PRODUTOS DA SUA DISSOCIAÇÃO; GORDURAS } \\
\text { ALIMENTARES }\end{array}$ & 16.022 & 12.285 & 10.809 \\
\hline $\begin{array}{l}\text { LEITE E LATICÍNIOS; OVOS DE AVES; MEL } \\
\text { NATURAL; PRODUTOS COMESTÍVEIS DE ORIGEM } \\
\text { ANIMAL }\end{array}$ & 4.142 & 3.123 & 4.524 \\
\hline $\begin{array}{l}\text { PELES, EXCETO A PELETERIA (PELES COM } \\
\text { PÊLO*), E COUROS }\end{array}$ & 12.937 & 9.983 & 4.381 \\
\hline $\begin{array}{l}\text { PRODUTOS DIVERSOS DAS INDÚSTRIAS } \\
\text { QUIIMICAS }\end{array}$ & 3.696 & 3.838 & 3.404 \\
\hline OUTROS PRODUTOS & 199.180 & 169.665 & 125.816 \\
\hline TOTAL & 565.295 & 1.496 .795 & 3.252 .123 \\
\hline \multicolumn{4}{|l|}{ IMPORTAÇÕES } \\
\hline $\begin{array}{l}\text { COMBUSTÍVEIS MINERAIS, ÓLEOS MINERAIS E } \\
\text { PRODUTOS DE SUA DESTILAÇÃO; MATÉRIAS } \\
\text { BETUMINOSAS }\end{array}$ & 3.974 .217 & 5.183 .726 & 5.670 .434 \\
\hline FERRO FUNDIDO, FERRO E AÇO & 429.652 & 272.959 & 206.950 \\
\hline $\begin{array}{l}\text { SAL; ENXOFRE; TERRAS E PEDRAS; GESSO, CAL } \\
\text { E CIMENTO }\end{array}$ & 173.866 & 24.886 & 84.474 \\
\hline ADUBOS OU FERTILIZANTES & 44.715 & 43.942 & 43.393 \\
\hline ALGODÃO & 6.626 & 27.662 & 35.859 \\
\hline PLÁSTICOS E SUAS OBRAS & 28.871 & 24.499 & 27.599 \\
\hline
\end{tabular}




\begin{tabular}{|c|c|c|c|}
\hline MOVIMENTAÇÃO & 2015 & 2016 & 2017 \\
\hline BORRACHA E SUAS OBRAS & 15.492 & 12.602 & 16.693 \\
\hline $\begin{array}{l}\text { PRODUTOS DIVERSOS DAS INDÚSTRIAS } \\
\text { QUÍMICAS }\end{array}$ & 25.283 & 27.224 & 16.435 \\
\hline $\begin{array}{l}\text { FIBRAS SINTÉTICAS OU ARTIFICIAIS, } \\
\text { DESCONTÍNUAS }\end{array}$ & 24.253 & 21.205 & 15.991 \\
\hline $\begin{array}{l}\text { MÁQUINAS, APARELHOS E MATERIAIS } \\
\text { ELÉTRICOS, E SUAS PARTES; APARELHOS DE } \\
\text { GRAVAÇÃO OU DE REPRODUÇÃO DE IMAGEM E } \\
\text { DE TELEVISÃO }\end{array}$ & 11.281 & 9.295 & 15.688 \\
\hline FILAMENTOS SINTÉTICOS OU ARTIFICIAIS & 12.269 & 15.567 & 14.155 \\
\hline $\begin{array}{l}\text { PAPEL E CARTÃO; OBRAS DE PASTA DE } \\
\text { CELULOSE, DE PAPEL OU DE CARTÃO }\end{array}$ & 23.634 & 12.005 & 11.575 \\
\hline OUTROS PRODUTOS & 631.106 & 220.690 & 192.543 \\
\hline TOTAL & 5.401 .264 & 5.896 .262 & 6.351 .789 \\
\hline
\end{tabular}

Quadro 3. Movimentação de mercadoria por tipo de carga no Porto do Pecém (2017). Fonte: CEARÁPORTOS (2017).

\begin{tabular}{|c|c|c|c|}
\hline MOVIMENTAÇÃO & EXPORT. & IMPORT. & TOTAL \\
\hline \multicolumn{4}{|l|}{ CARGA SOLTA } \\
\hline FERRO FUNDIDO, FERRO E AÇO & 2.654 .071 & 452.628 & 3.106 .699 \\
\hline $\begin{array}{l}\text { MÁQUINAS, APARELHOS E MATERIAIS } \\
\text { ELÉTRICOS, E SUAS PARTES; APARELHOS DE } \\
\text { GRAVAÇÃO OU DE REPRODUÇÃO DE SOM }\end{array}$ & 3.044 & 1.724 & 4.769 \\
\hline BORRACHA E SUAS OBRAS & - & 2.044 & 2.044 \\
\hline OBRAS DE FERRO FUNDIDO, FERRO OU AÇO & 333 & 1.436 & 1.769 \\
\hline OUTROS PRODUTOS & 108 & 1.496 & 1.604 \\
\hline TOTAL & 2.657 .557 & 459.329 & 3.116 .886 \\
\hline \multicolumn{4}{|l|}{ CARGA CONTEINERIZADA } \\
\hline $\begin{array}{l}\text { SAL; ENXOFRE; TERRAS E PEDRAS; GESSO, CAL } \\
\text { E CIMENTO }\end{array}$ & 252.179 & 43.184 & 295.363 \\
\hline CEREAIS & 18.872 & 219.768 & 238.640 \\
\hline PLÁSTICOS E SUAS OBRAS & 69.773 & 135.039 & 204.813 \\
\hline FRUTAS; CASCAS DE CÍTRICOS E DE MELÕES & 201.996 & 694 & 202.690 \\
\hline $\begin{array}{l}\text { PRODUTOS DA INDÚSTRIA DE MOAGEM; MALTE; } \\
\text { AMIDOS E FÉCULAS; INULINA; GLÚTEN DE } \\
\text { TRIGO }\end{array}$ & 123.143 & 8.330 & 131.473 \\
\hline $\begin{array}{l}\text { PAPEL E CARTÃO; OBRAS DE PASTA DE } \\
\text { CELULOSE, DE PAPEL OU DE CARTÃO }\end{array}$ & 5.569 & 106.711 & 112.280 \\
\hline FERRO FUNDIDO, FERRO E AÇO & 11.126 & 84.235 & 95.362 \\
\hline PREPARAÇÕES ALIMENTÍCIAS DIVERSAS & 73.155 & 10.968 & 84.123 \\
\hline $\begin{array}{l}\text { MADEIRA, CARVÃO VEGETAL E OBRAS DE } \\
\text { MADEIRA }\end{array}$ & 8.773 & 38.621 & 47.394 \\
\hline BEBIDAS, LÍQUIDOS ALCOÓLICOS E VINAGRES & 22.837 & 20.154 & 42.991 \\
\hline OUTROS PRODUTOS & 412.402 & 412.402 & 1.042 .894 \\
\hline TOTAL & 1.199 .827 & 1.298 .195 & 2.498 .022 \\
\hline
\end{tabular}




\begin{tabular}{|c|c|c|c|}
\hline MOVIMENTAÇÃO & EXPORT. & IMPORT. & TOTAL \\
\hline \multicolumn{4}{|l|}{ GRANEL LÍQUIDO } \\
\hline $\begin{array}{l}\text { COMBUSTÍVEIS MINERAIS, ÓLEOS MINERAIS E } \\
\text { PRODUTOS DE SUA DESTILAÇÃO; MATÉRIAS } \\
\text { BETUMINOSAS; CERAS MINERAIS }\end{array}$ & 184.986 & 782.491 & 967.477 \\
\hline OUTROS PRODUTOS & - & - & - \\
\hline TOTAL & 184.986 & 782.491 & 967.477 \\
\hline \multicolumn{4}{|l|}{ GRANEL SÓLIDO } \\
\hline $\begin{array}{l}\text { COMBUSTÍVEIS MINERAIS, ÓLEOS MINERAIS E } \\
\text { PRODUTOS DE SUA DESTILAÇÃO; MATÉRIAS } \\
\text { BETUMINOSAS; CERAS MINERAIS }\end{array}$ & & 4.954 .087 & 4.954 .087 \\
\hline MINÉRIOS, ESCÓRIAS E CINZA & & 4.201 .176 & 4.201 .176 \\
\hline OUTROS PRODUTOS & & 71.313 & 71.313 \\
\hline TOTAL & & 9.226 .576 & 9.226 .576 \\
\hline
\end{tabular}

O Quadro 3 apresenta a movimentação no ano de 2017 por tipo de carga, no intuito de apresentar a diversificação deste movimento a partir da capacidade do porto. É evidente a expansão na capacidade de movimentação de cargas conteinerizadas, um dos principais aspectos do transporte marítimo moderno. Como lembram Lima e Batista (2005) a conteinerização sintetiza o caráter moderno e de eficiência em capacidade de carga (volume, rapidez, acondicionamento). O uso dos contêineres impactou fortemente a evolução do comércio internacional principalmente a partir dos anos 1970, por sua capacidade de articular estruturas e processos produtivos dispersos pelo globo ao passo que "integrando clientes e funções geograficamente muito distantes teve efeitos imediatos e intensos sobre o espaço de circulação das mercadorias" (Monié, 2015:108).

Tais dados reforçam as assertivas de que o território e a economia cearenses passam por avanços na oferta de fixos que intensificam seus fluxos em âmbito global. No geral, a concepção do CIPP se tornou próprio ativo de reestruturação/reordenamento da economia do estado, signo do processo de modernização competitiva pautado no paradigma de eficiência econômica e o colocando nas fronteiras mais atrativas para as capitais transnacionais.

\section{Considerações finais}

As preocupações do presente trabalho voltaram-se para a compreensão das transformações requeridas pela reestruturação econômica, dentre elas os atributos de infraestrutura tornando territórios periféricos em plataformas da rede de geração de valor agregado produtivo, conforme atestou Monié (2011). O caso de referência foi a implantação do moderno Complexo Industrial e Portuário do Pecém, na Região Metropolitana de Fortaleza.

Dentre as principais expressões reveladas, confirmou-se a hipótese de que este grande projeto de infraestrutura equipou o território do estado do Ceará para novas rodadas do capitalismo, em que a produção multilocalizada requereu instrumentos de eficiência para efetivá-la. A constituição de um porto moderno, com alta capacidade, dispondo de vantagens locacionais e incentivos criados aos investimentos para comércio exterior como o caso da ZPE, são emblemáticos. 
A expansão dos indicadores de comércio exterior revelada pelos dados coloca o Ceará como ambiente de especialização na finalização de produção de matérias-primas semielaboradas como aço e ferro e, como espaço de produção primária da fruticultura irrigada. A limitada diversificação da estrutura produtiva estadual se torna mais competitiva com a disponibilidade do CIPP, embora seus avanços de conexão territorial dada pela infraestrutura privilegie a conexão de economias ganhadoras com o mundo, reforçando ainda a heterogeneidade econômica. Apesar da diversificação promovida no contexto da economia cearense, o papel da economia nacional no âmbito da divisão internacional do trabalho é reforçado com este equipamento por contribuir no fortalecimento de fornecedores de produtos primários, semimanufaturados e da indústria de bens de consumo não duráveis.

Para finalizar, destaca-se a importância do conjunto de trabalhos e análises acerca dos impactos ambientais deste grande projeto, dentre eles Alcântara e Avelino (2013), Tais impactos e seu monitoramento são questões que não podem ser omitidas e tão pouco deixar de ser mencionadas por não se tratar do objetivo do presente trabalho ${ }^{6}$. A maioria dos estudos sinaliza para efeitos de magnitudes amplas, de ordem natural, alterando o ecossistema pela implantação de plantas industriais e também pela expansão da urbanização em áreas lindeiras ao complexo. 


\section{Q Bibliografia}

》 ADECE. Governo do Estado do Ceará. Agência de Desenvolvimento do Ceará. Recuperado de: http://www.adece.ce.gov.br/index.php/porto-do-pecem 12/10/2018.

》 Alcântara, S. M. P. e Avelino, F. R. F. (2013). Transformações socioambientais: uma visão sobre o desenvolvimento do Pecém. Revista Gestão \& Desenvolvimento. 1 (1). s.p.

"Amaral Filho, J. do (2003). Ajustes estruturais, novas formas de intervenção pública e novo regime de crescimento econômico no Ceará. En: Gonçalves, M. F., Brandão, C. A. e Galvão, A. C. (Eds.). Regiões e cidades, cidades nas regiões: 0 desafio urbano-regional. (368-385) São Paulo: UNESP-ANPUR.

"ANTAQ. República Federativa do Brasil. Agência Nacional de Transportes Aquaviários. Recuperado de: http://antaq.gov.br/Portal/Anuarios/ Portuario2009/termos.htm (13/11/2018).

» Azenha, C. e Pequeno, L. R. B. (2016). O Porto do Pecém - CE, e as suas relações com o Brasil: definição de uma hinterlândia. Revista GeoUERJ 29, 44-62.

》Biachi, A. P. T. (2015). Condicionantes e articulações dos investimentos do Complexo Portuário de Suape - PE. Campinas, SP: Instituto de Economia da UNICAMP, 2015. (Dissertação de Mestrado).

» Bonfim, W. L. de S. (2001). Industrialização, planejamento estatal e o paradoxo da economia cearense. Revista Políticas Públicas e Sociedade. UECE. 1 (2), 102115 .

»Cain, L. P. (1997). Historical perspective on infrastructure and US economic development. Regional Science and Urban Economics 27, 117-138.

"Cano, W. (2007) Raízes da concentração industrial em São Paulo. $5^{\mathrm{a}}$. Ed. Campinas: Editora UNICAMP.

" CEARÁPORTOS. Governo do Estado do Ceará. Companhia de Integração Portuária do Ceará. Recuperado de: http://www.cearaportos.ce.gov.br/ (27/10/2018).

» CEARÁPORTOS. Governo do Estado do Ceará. Companhia de Integração Portuária do Ceará. Mensário Estatístico 2017. Recuperado de: http://www. cearaportos.ce.gov.br/ (12/10/2018).

" Crescenzi, R. e Roriguez-Posi, A. (2012). Infrastructure and regional growth in the European Union. Papers in Regional Science, 91 (3), 447-513.

»D’Emurger, S. (2001). Infrastructure Development and Economic Growth: An Explanation for Regional Disparities in China? Journal of Comparative Economics. 29, 95-117.

» laquinto, K. (2012). A reinvenção da ZPE. Conjuntura Econômica Rio de Janeiro. $66(6), 52-57$.

"IPEA. (2010). Infraestrutura Econômica no Brasil: diagnósticos e perspectivas para 2025. Projeto Perspectivas do Desenvolvimento Brasileiro. 6 (1). Brasília: IPEA.

»Lemoso, L. P. (2009). A infra-estrutura como elemento organizador do território. En: Silveira, M. R., Lamoso, L. P. e Mourão, P. F. C., Questões nacionais 
e regionais o território brasileiro. (43-62). São Paulo: Editora Expressão Popular.

» Lima Júnior, F. do O' de (2014). Estrutura produtiva e rede urbana no Estado do Ceará durante o período de 1980-2010. Campinas/SP: Instituto de Economia. (Tese de Doutoramento).

»Lima, L. C. e Batista, F. G. (2005). O porto na nova organização da produção mundial. X Encontro de Geógrafos da América Latina, São Paulo, Brasil. 77217732.

" Macedo, F. C. de (2015). Economia, transformações territoriais e infraestrutura no Brasil. Revista Conjuntura e Planejamento, 188, 43-51.

» Majumder, R. (2004). Infraestructure and Regional Development in India. Munich Personal RePEc Archive.

" McCann, P.; Shefer, D. (2004). Location, agglomeration and infrastructure. En: Florax, R. J. G. M. e Plane, D. A. (Eds.) Fifty years of Regional Science. (177-196) Berlin-Heidelbeg: Spriger-Verlag, 2004.

" Monié, F. (2011) Globalização, modernização do sistema portuário e relações cidade-porto no Brasil. En: Circulação, transportes e logística: diretivas perspectivas. (299-330) Silveira, M. R. (Eds.). São Paulo: Outras Expressões.

"Monié, F. (2015) As cidades portuárias diante do imperativo de fluidez, território, circulação e reestruturação das hinterlândias dos portos. En: Arroyo, M.; Cruz, R. de C. A. da (Eds.) Território e circulação: a dinâmica contraditória da globalização (103-128). São Paulo: FAPESP/PPGH/CAPES/ AnnaBlume Geografia.

» Morais, J. M. L.; Macedo, F., C. de. e Lima Júnior, F. do O’ de. (2014) Ceará: Economia, Urbanização e Metropolização. Crato, CE: RDS Editora.

"Shia, Y., Guob, S., Sunc, P. (2017). The role of infrastructure in China's regional economic growth. Journal of Asian Economics 49, 26-41.

"Silva, J. R. da.; Miranda, P. de T. C.; Pitombeira, S., C. e Freire. G. S. de S. (2014) Complexo Industrial e Portuário do Pecém, Município de São Gonçalo do Amarante, Ceará-Brasil: considerações em torno de sua avaliação ambiental estratégica. Arquivos Ciência do Mar. Fortaleza. 47 (2), 86-93.

» Silveira, M. R. (2015). Circulação, transportes, logística e a dinâmica capitalista: alguns apotamenos sobre as recentes reestruturações no Brasil. En: Arroyo, M.; Cruz, R. de C. A. da (Eds.) Território e circulação: a dinâmica contraditória da globalização (51-73). São Paulo: FAPESP/PPGH/CAPES/ AnnaBlume Geografia.

"Silveira, M. R. (2009). As cinco revoluções e evoluções logísticas e seus impactos sobre o território brasileiro. En: Silveira, M. R., Lamoso, L. P. e Paulo, F. C. M. Questões nacionais e regionais o território brasileiro. (13-42). São Paulo: Editora Expressão Popular.

»Snieska, V.; Simkunaite, I. (2009). Socio-Economic Impact of Infrastructure Investments. Inzinerine Ekonomika-Engineering Economics 3, 16-25.

"Teles, G. A. (2015). Mobilidade, trabalho e interações sócioespaciais: o Complexo Industrial e Portuário do Pecém - CIPP no contexto da Região Metropolitana de Fortaleza. Fortaleza/CE: Universidade Estadual do Ceará. Centro de Ciências da Tecnologia, Programa de Pós-graduação em Geografia. (Dissertação de Mestrado). 


\section{Francisco do O’ de Lima Júnior / lima.junior@urca.br}

Bacharel em Ciências Econômicas (Universidade Regional do Cariri - URCA). Mestre em Economia (Instituto de Economia, Universidade Federal de Uberlândia - IE-UFU/ $\mathrm{MG}$ ). Doutor em Desenvolvimento Econômico (Instituto de Economia, Universidade Estadual de Campinas/SP - IE-UNICAMP/SP). Estágio Doutoral Sanduíche (Instituto de Geografia - Universidade de Innsbruck, Áustria). Professor do Departamento de Economia da URCA.

\section{Fernando Cezar de Macedo Mota / fernando.cezar.macedo@gmai.com}

Bacharel em Ciências Econômicas (Universidade Federal do Espírito Santo - UFES). Mestre em Economia pela Universidade Federal do Espírito Santo. Doutor em Economia Aplicada (Instituto de Economia da Universidade Estadual de Campinas/SP - IEUNICAMP/SP). Professor Livre-docente em Economia Brasileira na área de Política Econômica e Desenvolvimento Regional pelo IE-UNICAMP.

\section{Denis Fernandes Alves / denis.fernandes@outlook.com}

Bacharel em Ciências Econômicas (Universidade Regional do Cariri - URCA). Mestre em Economia (Programa de Pós-graduação em Economia da Universidade Federal do Rio Grande do Norte -PPGECO-UFRN). Doutorando em Economia (Programa de Pós-graduação em Economia da Universidade Federal do Pernambuco - PIMES/ UFPE). Pesquisador do Grupo de Territorialidades Econômicas e Desenvolvimento Regional e Urbano (GETEDRU-URCA). 